\title{
Damage control resuscitation: a practical approach for severely hemorrhagic patients and its effects on trauma surgery
}

\author{
Yasumitsu Mizobata]
}

\begin{abstract}
Coagulopathy observed in trauma patients was thought to be a resuscitation-associated phenomenon. The replacement of lost and consumed coagulation factors was the mainstay in the resuscitation of hemorrhagic shock for many decades. Twenty years ago, damage control surgery (DCS) was implemented to challenge the coagulopathy of trauma. It consists of three steps: abbreviated surgery to control the hemorrhage and contamination, resuscitation in the intensive care unit (ICU), and planned re-operation with definitive surgery. The resuscitation strategy of DCS focused on the rapid reversal of acidosis and prevention of hypothermia through the first two steps. However, direct treatment of coagulopathy was not emphasized in DCS.

Recently, better understanding of the pathophysiology of coagulopathy in trauma patients has led to the logical opinion that we should directly address this coagulopathy during major trauma resuscitation. Damage control resuscitation (DCR), the strategic approach to the trauma patient who presents in extremis, consists of balanced resuscitation, hemostatic resuscitation, and prevention of acidosis, hypothermia, and hypocalcemia. In balanced resuscitation, fluid administration is restricted and hypotension is allowed until definitive hemostatic measures begin. The administration of blood products consisting of fresh frozen plasma, packed red blood cells, and platelets, the ratio of which resembles whole blood, is recommended early in the resuscitation. DCR strategy is now the most beneficial measure available to address trauma-induced coagulopathy, and it can change the treatment strategy of trauma patients. DCS is now incorporated as a component of DCR. DCR as a structured intervention begins immediately after rapid initial assessment in the emergency room and progresses through the operating theater into the ICU in combination with DCS. By starting from ground zero with the performance of DCS, DCR allows the trauma surgeon to correct the coagulopathy of trauma. The effect of the reversal of coagulopathy in massively hemorrhagic patients may change the operative strategy with DCS.
\end{abstract}

Keywords: Damage control resuscitation, Acute traumatic coagulopathy, Massive transfusion protocol, Damage control surgery, Balanced resuscitation

\section{Background}

Massive bleeding following injury remains the main cause of death in trauma patients. Uncontrolled hemorrhage is reported to be responsible for $40 \%$ of trauma deaths [1]. The central measure for controlling such bleeding incorporated physical hemostatic approaches, such as surgery or interventional radiology. Coagulopathy had been thought to be a resuscitation-induced phenomenon, and

Correspondence: mizobata@med.osaka-cu.ac.jp

Department of Traumatology and Critical Care Medicine, Graduate School of Medicine, Osaka City University, 1-4-3 Asahimachi, Abeno-ku, Osaka City, Osaka 545-8585, Japan replacement of the lost and consumed coagulation factors was the mainstay in the resuscitation of hemorrhagic shock. Recently, better understanding of the pathophysiology of coagulopathy in trauma patients has led to the logical opinion that we should directly address coagulopathy during major trauma resuscitation. Damage control resuscitation (DCR) is a strategic approach to the trauma patient who presents in extremis. In this review article, the pathophysiology of the coagulopathy in trauma patients, the theoretical and practical aspects of DCR, and the revolution of damage control surgery (DCS) incorporated with DCR are discussed. 


\section{Coagulopathy in trauma}

\section{Resuscitation-associated coagulopathy}

Traditionally, the coagulopathy observed in trauma patients was thought to be "resuscitation-associated coagulopathy," which is caused by the consumption of coagulation factors, dilution of coagulation factors after massive infusion, hypothermia, and acidosis. An increasing incidence of coagulopathy was observed with increasing amounts of intravenous fluids administered [2]. The administration of large amounts of fluids and blood products, exposure of the body, and surgical intervention performed for resuscitation cause the hypothermia. The alcohol and drugs, which are one of the causes of trauma incident, increase heat loss from the trauma patient. Hypothermia is observed in about $60 \%$ of trauma patients who require emergency operative interventions [3]. It is associated with platelet dysfunction and reduced enzyme activities [4] and an increased risk of bleeding and mortality of trauma patients [5]. Inadequate tissue perfusion due to hemorrhagic shock results in anaerobic metabolism and the subsequent production of lactic acid, which causes metabolic acidosis. The high chloride content in crystalloid solutions, such as $0.9 \%$ normal saline, exacerbates the metabolic acidosis $[6,7]$. The activity of most of the coagulation factors is dependent on the blood pH. For example, the activity of factors VIIa and $\mathrm{Xa} / \mathrm{Va}$ decreases by over $90 \%$ [8] and 70\% [9], respectively, when the blood $\mathrm{pH}$ decreases from 7.4 to 7.0.

\section{A vicious cycle}

In 1982, Kashuk and his colleagues emphasized the importance of coagulopathy in their clinical review of 161 patients with major abdominal vascular injury [10]. They reported that most of the deaths were a result of hemorrhage, and overt coagulopathy was identified in $51 \%$ of patients after vascular control was achieved.

The term "lethal triad" was used to describe the physiologic derangement observed in these patients and refers to the triad of the deteriorating status of acute coagulopathy, hypothermia, and acidosis of exsanguinating trauma patients. The lethal triad forms a downward spiral, and further hemorrhage deteriorates the triad. Unless this cycle can be broken, the patient's death is unavoidable. From this aspect, this downward spiral is known as the "vicious cycle of trauma" or the "bloody vicious cycle," which demands as much attention from the physician as the classically emphasized initial resuscitation and operative intervention.

\section{Acute traumatic coagulopathy}

Recently, injury itself is reported to cause early coagulopathy $[11,12]$, which is known as "trauma-induced coagulopathy" [13] or "acute traumatic coagulopathy (ATC)" [14]. ATC is an obvious early coagulopathy and occurs prior to significant dilution [14, 15], within $30 \mathrm{~min}$ of injury [12], and affects a quarter of the patients with severe trauma [14]. The patients with this coagulopathy have higher mortality than those with normal clotting function [14].

Although the pathophysiology of ATC is not fully understood, it is thought to occur following injury and concomitant hypoperfusion [16]. ATC is affected primarily through activated protein $\mathrm{C}$, which causes both anticoagulant effects and fibrinolytic effects by inhibiting plasminogen activator inhibitor-1. Instead of the importance of tissue factor, another group has argued that the coagulopathy in trauma is one of disseminated intravascular coagulation with a fibrinolytic phenotype, which is characterized by activation of the coagulation pathways, insufficient anticoagulation mechanisms, and increased fibrinolysis $[17,18]$.

These recent understandings of ATC have guided the principle and practice of DCR, which directly addresses the hemostatic dysfunction of the severely injured patient.

\section{Damage control resuscitation \\ Management of coagulopathy in trauma patients}

In the severely injured patient, unless the lethal triad of hypothermia, acidosis, and coagulopathy is prevented, death is unavoidable [19]. DCS is a resuscitation strategy that was devised to avoid these physiological disorders. It consists of three steps: abbreviated surgery to control the hemorrhage and contamination, resuscitation in the intensive care unit (ICU), and planned re-operation with definitive surgery [20]. The resuscitation strategy of DCS focused on the rapid reversal of acidosis and the prevention of hypothermia through the first two steps. However, direct treatment of coagulopathy was not emphasized in DCS. The coagulopathy observed in hemorrhagic patients was thought to be a result of resuscitation, acidosis, and hypothermia. Thus, the aim of DCS was to avoid the acidosis and hypothermia resulting from aggressive definitive surgery. Little attention was paid to the early derangement of coagulation function caused by the trauma itself. In contrast, DCR directly addresses the trauma-induced coagulopathy immediately upon patient admission [21] or in the pre-hospital setting [22]. DCR consists of balanced resuscitation, hemostatic resuscitation, and prevention of acidosis, hypothermia, and hypocalcemia.

\section{Balanced resuscitation}

The patient's response to the rapid infusion of isotonic fluid or blood is the indicator of the need for surgical or interventional hemostatic procedures. Aggressive fluid resuscitation was the initial fluid therapy recommended for many decades. However, this approach may contribute to increased blood loss and higher mortality [23]. The warning concerning the massive administration of fluid 
was already reported about 100 years ago by Captain Cannon [24]. He commented that, "There is no doubt that in some cases such injections have had definitely beneficial effects, however, the injection of a fluid, that will increase blood pressure, has dangers in itself. If the pressure is raised before the surgeon is ready to check any bleeding, blood needed may be lost."

Increasing evidence has shown that aggressive crystalloid-based resuscitation strategies are associated with cardiac and pulmonary complications [25], gastrointestinal dysfunction, coagulation disturbances, and disorders of immunological and inflammatory mediators [26]. The administration of large volumes of fluids results in imbalances of intracellular and extracellular osmolarity that affect cell volume. Disturbances in cell volume then disrupt numerous regulatory mechanisms responsible for controlling the inflammatory cascade.

For these reasons, an alternative approach to the treatment of hemorrhagic patients was recently proposed and practiced. The approach was introduced as permissive hypotension, delayed resuscitation, or controlled resuscitation. The aim of these resuscitation strategies is not hypotension but rather to balance the risk of decreased tissue perfusion with the benefits from the prevention of coagulopathy.

In 1994, Bickell and colleagues investigated the benefit of delayed fluid resuscitation in a randomized controlled trial. Five hundred eighty-nine adult patients with penetrating injuries and a pre-hospital systolic blood pressure of less than $90 \mathrm{mmHg}$ were enrolled in the trial [27]. The application of delayed fluid resuscitation increased the survival rate of of the patients from 62 to $70 \%$.

After this report, several randomized or retrospective studies concerning balanced resuscitation were reported; however, the benefit to mortality varied among the studies [28-31]. Turner et al. randomized more than 1000 patients to immediate or delayed resuscitation in the prehospital setting but showed no beneficial effects on mortality [28]. Both Dutton et al. and Morrison et al. investigated the effects of hypotensive resuscitation in about 100 patients, but the results varied between these two reports $[29,30]$. Duke et al. retrospectively compared cohorts with standard and restricted fluid resuscitation and reported that restricted fluid resuscitation showed a survival benefit [31].

When evaluating the effects of balanced resuscitation, these results should be interpreted cautiously. The patients enrolled in the Bickell et al. and Duke et al. reports were victims of penetrating injury only. In the reports of Morrison et al. and Dutton et al., the rates of patients with penetrating injury were 93 and 51\%, respectively. The time from hospital arrival to the emergency operation was very short, and furthermore, the patients were in their $20 \mathrm{~s}$ or 30 s. There are other concerns, such as the low protocol compliance in the Turner et al. report and the difficulty of controlling the blood pressure at the aimed-for level in the Dutton et al. and Morrison et al. reports.

The ninth edition of the Advanced Trauma Life Support emphasizes the concept of balanced resuscitation, and the term "aggressive resuscitation" has been eliminated. The standard use of $2 \mathrm{~L}$ of crystalloid resuscitation as the starting point for all resuscitation has been modified to the initiation of $1 \mathrm{~L}$ of crystalloid infusion. Early use of blood and blood products for patients in shock is emphasized [32].

The most recent randomized controlled trial to evaluate the efficacy of balanced resuscitation was reported in 2015 [33]. This multicenter study was performed in 19 emergency medical services systems in the USA and Canada. The controlled resuscitation resulted in a reduction of early crystalloid resuscitation volume and an increase in the early transfusion of blood products. Although mortality at $24 \mathrm{~h}$ was not different among all patients, it improved in the subgroup with blunt trauma. The controlled resuscitation strategy can be successfully and safely implemented in a civilian environment beginning with the out-of-hospital setting and extending into early hospital care.

\section{Hemostatic resuscitation}

In 2007, Borgman and Holcomb et al. reported a survival benefit for the high ratio of plasma to red blood cell $(\mathrm{RBC})$ in patients who received massive transfusions at a combat support hospital [34]. A high plasma to RBC ratio (1:1.4) was independently associated with improved survival, primarily by decreasing death from hemorrhage. Following this article, several studies investigating the survival benefit of a high ratio of fresh frozen plasma (FFP) to $\mathrm{RBC}$ were reported [35-40]. Although the ratio of FFP to $\mathrm{RBC}$ differed between the studies, a significant decrease in the mortality of the massively transfused patients in the high-ratio population as compared to the low-ratio population was achieved in both the civilian setting and the combat situation.

However, it remains controversial which ratio, $1: 1$ or $1: 2$, is beneficial and when the ratio should be achieved. Snyder et al. worried about the survival bias in the beneficial results observed in the retrospective studies [41]. Holcomb and colleagues investigated the relationship between in-hospital mortality and the early transfusion of plasma or platelets, and time variance in the delivery of plasma to $\mathrm{RBC}$ or platelet to $\mathrm{RBC}$ ratios in a multicenter prospective observational study [42]. The number of patients receiving the higher ratio rose as time passed. In the first $6 \mathrm{~h}$, patients receiving a ratio of less than 1:2 were three to four times more likely to die than patients receiving a ratio of $1: 1$ or higher. They concluded that 
the earlier and higher ratio of plasma to RBCs decreased in-hospital mortality, and this beneficial effect was enhanced when the high ratio was achieved in the first $6 \mathrm{~h}$ after admission. In the Japan-Observational study for Coagulation and Thrombolysis in Early Trauma (JOCTET), 189 severe trauma adult patients were registered [43]. Although the area under the curve was not high, the receiver operating characteristic curve analysis showed that the FFP/RBC ratio of 1.0 resulted in maximum sensitivity and specificity for survival. They concluded that a transfusion with an FFP/RBC ratio over 1.0 within the first $6 \mathrm{~h}$ reduces the risk of death by about $60 \%$ in patients with blunt hemorrhagic trauma.

The most recent randomized trial to evaluate the suitable ratio of plasma to RBCs for patients with severe trauma and major bleeding was performed in the pragmatic, randomized optimal platelet and plasma ratios (PROPPR) study [44], in which 680 patients were randomized to receive either a 1:1:1 or 1:1:2 ratio of plasma, platelets, and RBCs. Although the mortality was not significantly different between the two groups, more patients in the 1:1:1 group achieved hemostasis. Exsanguination, which was the predominant cause of death within the first $24 \mathrm{~h}$, was significantly decreased in the high-ratio group.

\section{Rewarming}

In DCR, hypothermia should be managed in conjunction with the efforts to correct the trauma-induced coagulopathy. It is essential to rewarm the torso using passive warming measures, such as insulting foil, blankets, and the removal of wet clothes. The initial fluid resuscitation should be carried out with warmed infusions at a fluid temperature of $40-42{ }^{\circ} \mathrm{C}[5,45]$. Heated air inhalation, gastric or body cavity lavage with warmed fluids, and heat radiation are widely performed as well as the standardized use of warming measures with rapid infusers. The temperature in the emergency room and the operating room should be raised, at best to a thermally neutral range $\left(28-29{ }^{\circ} \mathrm{C}\right)$ [46]. If the hypothermia persists or quickly relapses despite these maximal rewarming efforts, ongoing hemorrhage and unresolved tissue hypoperfusion and hypoxia should be suspected.

\section{Reversing acidosis}

Buffering of metabolic acidosis using drugs not only aggravates the intracellular acidosis but also does not reverse the coagulopathy [47]. Reversal of metabolic acidosis in the trauma patient is better obtained through fluid and blood resuscitation and vasopressor support with surgical control of hemorrhage. Shock should be reversed and end-organ perfusion is restored [48]. Because vital signs such as blood pressure and heart rate are not adequate to evaluate peripheral tissue perfusion, several endpoints of resuscitation are addressed. Base deficit and lactate levels are the reliable indices with which to evaluate the adequacy of the resuscitation and end-organ perfusion. Not only the initial lactate value upon admission but also lactate clearance from plasma within the first few hours of resuscitation correlate with the mortality of trauma patients $[49,50]$.

\section{Tranexamic acid}

Because hyperfibrinolysis was recognized to contribute to the acute coagulopathy in trauma, administration of antifibrinolytic agents had theoretical benefit. The clinical randomization of an antifibrinolytic in significant hemorrhage 2 (CRASH-2) study, a large multi-center randomized controlled trial, investigated the effect of tranexamic acid on mortality and blood product requirements in trauma patients with hemorrhagic shock [51]. The study was undertaken in 274 hospitals in 40 countries. More than 20,000 adult trauma patients were randomized to receive either tranexamic acid or placebo within $8 \mathrm{~h}$ of injury. All-cause mortality and the risk of death due to bleeding were significantly decreased with the administration of tranexamic acid. Maximal beneficial effects were achieved if it was given within the first $3 \mathrm{~h}$ of injury. However, a recent study indicated that the majority of severely injured patients have fibrinolysis shutdown, and therefore, tranexamic acid may have no effect $[52,53]$. The greatest benefit of tranexamic acid may be in patients in whom increased clot lysis is shown to be present using thromboelastography.

\section{Fibrinogen concentrates}

Fibrinogen plays a central role in the coagulation process. It bridges activated platelets and works as the key substrate of thrombin to generate a stable fibrin mesh. In patients with blood loss, fibrinogen has been reported to decrease more rapidly under critically low concentrations than the other coagulation factors [54]. Thus, the supplementation of fibrinogen is a measure that makes sense when treating the coagulopathy of trauma patients. The effect of the administration of fibrinogen concentrates on outcome was investigated by matched-pairs analysis using the German Trauma Registry [55]. Although 30-day mortality was comparable, 6-h mortality was significantly lower in the patients receiving fibrinogen. The fibrinogen concentrates might have delayed the cause of death from early hemorrhagic collapse to late multiple organ failure.

\section{Prothrombin complex concentrate}

Recently, prothrombin complex concentrate, derived from human plasma and contains variable amounts of factors II, VII, IX, and X, is used to correct coagulopathy $[56,57]$. Goal-directed coagulation management using 
thromboelastometry was used to evaluate requirements of clotting factors [56, 57]. The administration of fibrinogen concentrate alone or in combination with prothrombin complex concentrate resulted in a significant improvement of fibrin polymerization and shorter clotting time [56]. Schochl et al. used fibrinogen concentrate and prothrombin concentrate complex as first-line therapies for coagulopathy based on thromboelastography in a study of 131 severely injured patients [57]. Transfusion of fresh frozen plasma and cryoprecipitate was avoided in the vast majority of these patients and outcomes were better than predicted.

\section{Cryoprecipitate}

In the countries, where administration of fibrinogen concentrates is not approved in trauma patients, cryoprecipitate is the alternative treatment option as a source of fibrinogen. However, there are no reports suggesting positive effects of cryoprecipitate administration on the survival of exsanguinating trauma patients [58-60]. Although cryoprecipitate contains high concentrations of fibrinogen, it is hampered by several relevant disadvantages in terms of its availability, allogenicity, and the need for blood type matching and time-consuming thawing. Because the timing and indications for the administration of cryoprecipitate were unclear in the previously reported studies, a prospective randomized trial will be required to evaluate its benefit [59].

\section{Calcium}

Calcium acts as an important cofactor in the coagulation cascade. Low levels of ionized calcium at admission are associated with increased mortality and an increased requirement for massive transfusion [61, 62]. Citrate, which is used as an anticoagulant in blood product components, chelates calcium and exacerbates the hypocalcemia, particularly when used in the FFP. The faster the transfusion is given, the faster the reduction of the calcium concentration occurs [63]. An ionized calcium concentration of less than $0.6-0.7 \mathrm{mmol} / \mathrm{L}$ could lead to coagulation defects. In addition, contractility of the heart and systemic vascular resistance are diminished under decreased ionized calcium levels. Because of its combined beneficial cardiovascular and coagulation effects, the calcium concentration should be monitored periodically with every ten units of transfusion, and it is recommended that a concentration of at least $0.9 \mathrm{mmol} / \mathrm{L}$ be maintained $[64,65]$.

\section{Massive transfusion protocol}

Massive transfusion is typically defined as the transfusion of ten or more units of packed red blood cells within the first $24 \mathrm{~h}$ of injury. It is important for the resuscitation staff to identify the patients who might require massive transfusion early in the process of initial resuscitation. Following the prediction of massive transfusion, blood products should be delivered in a quick and timely manner at a high ratio of plasma, RBCs, and platelets. To achieve this quick response, not only the resuscitation staff but also the blood bank staff need to incorporate pre-implemented guidelines and flow charts for massive transfusion protocol (MTP) into their work flow [48, 66-68]. The protocol includes patient selection for activation of the MTP, description of the staff who should declare the activation, and the means by which the resuscitation team and the blood bank are informed of the protocol's activation. In the blood bank, cooled packs of $\mathrm{O}$ negative $\mathrm{RBCs}$, type $\mathrm{AB}$ FFP, and platelets will be pre-packed for quick delivery. A high-ratio pack is continually delivered each time blood is requested until the protocol is deactivated. Type-specific blood will be delivered as soon as the patient's blood type is determined.

The MTP was implemented in $85 \%$ of the trauma centers in the USA as of 2010 [69]. The MTP is bundled with the administration of calcium, factor VIIa, and fibrinogen. The laboratory examination of coagulation function by thromboelastography is included as are other standard blood laboratory tests.

The beneficial effects of the implementation of the MTP have been reported by several authors to be reductions in mortality and in the use of blood products $[67,70,71]$. Furthermore, compliance with the protocol affects patient outcome [66]. Because it is complex to transfuse blood products in a timely and safe manner, implementation of the MTP is essential for institutions caring for severely injured trauma patients. Improved blood bank procedures, effective and efficient rewarming procedures, application of damage control techniques, and aggressive correction of coagulopathy will contribute to the survival benefit [72].

It is important to activate the MTP as quickly as possible; however, it is worth considering that massive transfusion, especially with the administration of FFP, has adverse effects for a subgroup of trauma patients. Inaba and colleagues retrospectively investigated the incidence opportunity following plasma transfusion in patients who did not require massive transfusion [73]. Although there was no improvement in survival with plasma transfusion, the overall rate of complications was significantly higher in the patients receiving plasma products.

Several scores, such as the trauma associated severe hemorrhage (TASH) [74], the scoring system developed by McLaughlin [75], assessment of blood consumption (ABC) [76], and traumatic bleeding severity score (TBSS) [77] scores, are proposed for the prediction of patients who require massive transfusion in the early 
phase of resuscitation. Each score includes the systolic blood pressure and heart rate on admission or after the initial resuscitation. The focused assessment with sonography for trauma exam, extremity and/or pelvic injury, sex, age, or laboratory data are assessed to calculate these scores. Recently, the TBSS score was modified to predict the need for massive transfusion more quickly [78]. The systolic blood pressure on arrival but after fluid resuscitation was used. The predictive value of the modified TBSS is still high and is reported to be equivalent to that of the TASH score.

\section{Remote DCR}

The concept and practice of the DCR is recently applied in the pre-hospital setting and named as remote DCR (RDCR) [79]. Not only the fixed-ratio coagulation therapy using the high ratio of plasma and platelets to $\mathrm{pRBC}$ but also the coagulation factor concentrate-based treatment is proposed in the RDCR. It includes three major components to a step-wise approach to achieve hemostasis: (1) stop (hyper)fibrinolysis, tranexamic acid; (2) support clot formation, fibrinogen concentrate; and (3) increase thrombin generation, prothrombin complex concentrate [22]. Although RDCR warrants further investigation concerning its effect on the mortality or the blood products requirement, and the assessment of the patient's coagulation function in the instrument limited environment, the tranexamic acid has been implemented in the RDCR in the US, French, British, and Israeli militaries as well as the British, Norwegian, and Israeli civilian ambulance services. A prospective cohort study in the civilian trauma center demonstrated reduction in mortality and multiple organ failure for patients treated with tranexamic acid in the subgroup of patients with shock [80]. In the report of Wafaisade et al., the propensity score matched analysis using the German trauma database demonstrated the prolonged time to death and reduction in early mortality in the tranexamic acid-administered trauma patients [81]. The updated European guideline suggests the administration of the first dose of tranexamic acid en route to the hospital as a grade $2 \mathrm{C}$ recommendation [82].

\section{DCR and DCS}

\section{Adverse effects of DCS}

After the recognition of the vicious cycle in trauma patients, a paradigm shift in the surgical treatment of severely hemorrhagic patients occurred. DCS was developed to challenge the lethal triad of trauma. It was originally reported by Stone and colleagues in 1983 [83] and named by Rotondo and Schwab in 1993 [20]. Since these reports, DCS has become the standard of care for the most severely injured patients. It has been widely applied not only for abdominal trauma but also for thoracic [84], vascular [85], pelvic [86], and extremity injuries [87, 88]. DCS has led to better outcomes in severely hemorrhagic patients [89]. Ten years of experience have shown that patients who receive DCS for penetrating abdominal trauma have higher survival rates and a decreased incidence of hypothermia in the operating room [90]. In the early decades after DCS was introduced, it was performed in cooperation with aggressive volume resuscitation.

Although DCS was popularized and resulted in reduced mortality, the abbreviated surgical techniques and open abdomen management led to significant increases in sub-acute complications, such as open abdomen, acute respiratory distress syndrome, intra-abdominal infections, and multiple organ failure [91]. In particular, open abdomen management resulted in an increase in severe morbidities, such as anastomotic breakdown, ventral hernias, and enteroatmospheric fistula [92, 93]. Aggressive resuscitation increased the incidence of these complications [26].

Studies have recently warned against the overuse of DCS [94, 95]. Clinical outcomes may be improved with more selective use of DCS accompanied by DCR [96].

\section{Changes of surgical strategy in DCR}

The severely hemorrhagic patient has a limited amount of physiologic reserve before irreversible derangement, organ damage, and collapse occur. DCR restores this reserve, allowing more definitive treatment that results in decreased postoperative complications and improved outcomes $[40,68]$.

DCS is now incorporated as a component of DCR and should not be practiced in isolation [64]. DCR as a structured intervention should begin immediately after rapid initial assessment in the emergency room and progresses through the operating theater into the ICU in combination with DCS [48].

By starting from ground zero with the performance of DCS, DCR allows the trauma surgeon to correct the lethal triad, particularly the coagulopathy of trauma. Definitive therapy can be completed at the first operation in patients who are warm, well perfused, and without coagulopathy $[97,98]$.

Higa and colleagues reported that DCR increased the administration of blood products with less infusion of crystalloid solution and was associated with a survival advantage and shorter length of stay in the trauma ICU for patients with severe hemorrhage [96]. Although the number of laparotomy patients increased, the number of patients requiring damage control laparotomy decreased from 36 to $9 \%$, and the mortality for patients requiring open laparotomy improved from 22 to $13 \%$. The application of DCR to damage control laparotomy techniques results in an improvement in the ability to achieve primary fascia closure and decreases the requirement for 
staged laparotomy [99]. In addition, DCR may decrease the surgical hemostatic requirement in severely injured patients. A retrospective study showed an increase in the success rate of nonoperative management from 54 to $74 \%$ for grades IV and V severe blunt liver injury after the implementation of DCR [100]. DCR may herald the beginning of the end for DCS [98].

\section{Conclusions}

DCR strategy is the measure that directly addresses trauma-induced coagulopathy. Although several concerns, such as the plasma to RBCs ratio, the method of achieving balanced resuscitation, and the administration of other coagulation factors, are not completely resolved, it is now the most beneficial measure for treating trauma-induced coagulopathy, and it can change the treatment strategy of trauma patients. The effect of the reversal of coagulopathy in the massively hemorrhagic patient may shift the operative strategy from one of DCS to definitive surgery.

\section{Abbreviations}

ABC: Assessment of blood consumption; ATC: Acute traumatic coagulopathy; CRASH-2: Clinical randomization of an antifibrinolytic in significant hemorrhage 2; DCR: Damage control resuscitation; DCS: Damage control surgery; FFP: Fresh frozen plasma; ICU: Intensive care unit; J-OCTET: Japanobservational study for coagulation and thrombolysis in early trauma; MTP: Massive transfusion protocol; PROPPR: Pragmatic, randomized optimal platelet and plasma ratios; RBC: Red blood cell; RDCR: Remote damage control resuscitation; TASH: Trauma associate severe hemorrhage; TBSS: Traumatic bleeding severity score

\section{Acknowledgements}

Not applicable.

\section{Funding}

No funding

\section{Availability of data and materials}

Data sharing not applicable to this article as no datasets were generated or analyzed during the current study.

\section{Authors' contributions}

YM wrote, read, and approved the final manuscript.

\section{Competing interests}

The author declares that he/she has no competing interests.

\section{Consent for publication}

Not applicable.

\section{Ethics approval and consent to participate}

Not applicable.

Received: 1 September 2016 Accepted: 17 December 2016

Published online: 20 January 2017

\section{References}

1. Sauaia A, Moore FA, Moore EE, Moser KS, Brennan R, Read RA, et al. Epidemiology of trauma deaths: a reassessment. J Trauma. 1995;38(2):185-93.

2. Maegele M, Lefering R, Yucel N, Tjardes T, Rixen D, Paffrath T, et al. Early coagulopathy in multiple injury: an analysis from the German Trauma Registry on 8724 patients. Injury. 2007;38(3):298-304.

3. Gregory JS, Flancbaum L, Townsend MC, Cloutier CT, Jonasson O. Incidence and timing of hypothermia in trauma patients undergoing operations. J Trauma. 1991;31 (6):795-8. discussion 798-800.
4. Wolberg AS, Meng ZH, Monroe 3rd DM, Hoffman M. A systematic evaluation of the effect of temperature on coagulation enzyme activity and platelet function. J Trauma. 2004;56(6):1221-8.

5. Beekley AC. Damage control resuscitation: a sensible approach to the exsanguinating surgical patient. Crit Care Med. 2008;36(7 Suppl):S267-74.

6. Besen BA, Gobatto AL, Melro LM, Maciel AT, Park M. Fluid and electrolyte overload in critically ill patients: an overview. World J Crit Care Med. 2015:4(2):116-29.

7. Santi M, Lava SA, Camozzi P, Giannini O, Milani GP, Simonetti GD, et al. The great fluid debate: saline or so-called "balanced" salt solutions? Ital J Pediatr. 2015;41:47.

8. Meng ZH, Wolberg AS, Monroe 3rd DM, Hoffman M. The effect of temperature and $\mathrm{pH}$ on the activity of factor VIlla: implications for the efficacy of high-dose factor VIla in hypothermic and acidotic patients. J Trauma. 2003;55(5):886-91.

9. Martini WZ. Coagulopathy by hypothermia and acidosis: mechanisms of thrombin generation and fibrinogen availability. J Trauma. 2009;67(1):202-8. discussion 208-9.

10. Kashuk JL, Moore EE, Millikan JS, Moore JB. Major abdominal vascular trauma-a unified approach. J Trauma. 1982;22(8):672-9.

11. Hess JR, Brohi K, Dutton RP, Hauser CJ, Holcomb JB, Kluger Y, et al. The coagulopathy of trauma: a review of mechanisms. J Trauma. 2008;65(4):748-54.

12. Floccard B, Rugeri L, Faure A, Saint Denis M, Boyle EM, Peguet O, et al. Early coagulopathy in trauma patients: an on-scene and hospital admission study. Injury. 2012;43(1):26-32.

13. Chang R, Cardenas JC, Wade CE, Holcomb JB. Advances in the understanding of trauma-induced coagulopathy. Blood. 2016;128(8):1043-9.

14. Brohi K, Singh J, Heron M, Coats T. Acute traumatic coagulopathy. J Trauma. 2003;54(6):1127-30

15. MacLeod JB, Lynn M, McKenney MG, Cohn SM, Murtha M. Early coagulopathy predicts mortality in trauma. J Trauma. 2003;55(1):39-44.

16. Brohi K, Cohen MJ, Ganter MT, Matthay MA, Mackersie RC, Pittet JF. Acute traumatic coagulopathy: initiated by hypoperfusion: modulated through the protein C pathway? Ann Surg. 2007;245(5):812-8.

17. Gando S, Wada H, Kim HK, Kurosawa S, Nielsen JD, Thachil J, et al. Comparison of disseminated intravascular coagulation in trauma with coagulopathy of trauma/acute coagulopathy of trauma-shock. J Thromb Haemost. 2012;10(12):2593-5.

18. Gando S, Wada H, Thachil J. Scientific, Standardization Committee on DICotISoT, Haemostasis. Differentiating disseminated intravascular coagulation (DIC) with the fibrinolytic phenotype from coagulopathy of trauma and acute coagulopathy of trauma-shock (COT/ACOTS). J Thromb Haemost. 2013;11(5):826-35.

19. Moore EE. Staged laparotomy for the hypothermia, acidosis, and coagulopathy syndrome. Am J Surg. 1996;172:405-10.

20. Rotondo MF, Schwab CW, McGonigal MD, Phillips 3rd GR, Fruchterman TM, Kauder DR, et al. 'Damage control': an approach for improved survival in exsanguinating penetrating abdominal injury. J Trauma. 1993;35(3):375-82. discussion 382-3.

21. Ho AM, Karmakar MK, Dion PW. Are we giving enough coagulation factors during major trauma resuscitation? Am J Surg. 2005;190(3):479-84.

22. Maegele M. Coagulation factor concentrate-based therapy for remote damage control resuscitation (RDCR): a reasonable alternative? Transfusion. 2016;56 Suppl 2:S157-65.

23. Rezende-Neto JB, Rizoli SB, Andrade MV, Ribeiro DD, Lisboa TA, Camargos ER, et al. Permissive hypotension and desmopressin enhance clot formation. J Trauma. 2010;68(1):42-50.

24. Cannon WB, Fraser J, Cowell EM. The preventive treatment of wound shock. JAMA. 1918;70:618-21.

25. Brandstrup B, Tonnesen H, Beier-Holgersen R, Hjortso E, Ording H, LindorffLarsen $\mathrm{K}$, et al. Effects of intravenous fluid restriction on postoperative complications: comparison of two perioperative fluid regimens: a randomized assessor-blinded multicenter trial. Ann Surg. 2003;238(5):641-8.

26. Cotton BA, Guy JS, Morris Jr JA, Abumrad NN. The cellular, metabolic, and systemic consequences of aggressive fluid resuscitation strategies. Shock. 2006;26(2):115-21.

27. Bickell WH, Wall Jr MJ, Pepe PE, Martin RR, Ginger VF, Allen MK, et al. Immediate versus delayed fluid resuscitation for hypotensive patients with penetrating torso injuries. N Eng J Med. 1994;331(17):1105-9.

28. Turner J, Nicholl J, Webber L, Cox H, Dixon S, Yates D. A randomised controlled trial of prehospital intravenous fluid replacement therapy in serious trauma. Health Technol Assess. 2000;4(31):1-57. 
29. Dutton RP. Low-pressure resuscitation from hemorrhagic shock. Int Anesthesiol Clin. 2002;40(3):19-30.

30. Morrison CA, Carrick MM, Norman MA, Scott BG, Welsh FJ, Tsai P, et al. Hypotensive resuscitation strategy reduces transfusion requirements and severe postoperative coagulopathy in trauma patients with hemorrhagic shock: preliminary results of a randomized controlled trial. J Trauma. 2011;70(3):652-63.

31. Duke MD, Guidry C, Guice J, Stuke L, Marr AB, Hunt JP, et al. Restrictive fluid resuscitation in combination with damage control resuscitation: time for adaptation. J Trauma Acute Care Surg. 2012;73(3):674-8.

32. The ATLS subcommittee, American College of Surgeons' Committee on Trauma, and International ATLS working group. Advanced trauma life support (ATLS(R)): the ninth edition. J Trauma Acute Care Surg. 2013;74(5):1363-6.

33. Schreiber MA, Meier EN, Tisherman SA, Kerby JD, Newgard CD, Brasel K, et al. A controlled resuscitation strategy is feasible and safe in hypotensive trauma patients: results of a prospective randomized pilot trial. J Trauma Acute Care Surg. 2015;78(4):687-95. discussion 695-7.

34. Borgman MA, Spinella PC, Perkins JG, Grathwohl KW, Repine T, Beekley AC, et al. The ratio of blood products transfused affects mortality in patients receiving massive transfusions at a combat support hospital. J Trauma. 2007;63(4):805-13.

35. Holcomb JB, Wade CE, Michalek JE, Chisholm GB, Zarzabal LA, Schreiber MA, et al. Increased plasma and platelet to red blood cell ratios improves outcome in 466 massively transfused civilian trauma patients. Ann Surg. 2008;248(3):447-58.

36. Duchesne JC, Hunt JP, Wahl G, Marr AB, Wang YZ, Weintraub SE, et al. Review of current blood transfusions strategies in a mature level I trauma center: were we wrong for the last 60 years? J Trauma. 2008;65(2):272-6. discussion 276-8.

37. Kashuk JL, Moore EE, Johnson JL, Haenel J, Wilson M, Moore JB, et al. Postinjury life threatening coagulopathy: is 1:1 fresh frozen plasma:packed red blood cells the answer? J Trauma. 2008;65(2):261-70. discussion 270-1.

38. Sperry JL, Ochoa JB, Gunn SR, Alarcon LH, Minei JP, Cuschieri J, et al. An FFP: PRBC transfusion ratio $>/=1: 1.5$ is associated with a lower risk of mortality after massive transfusion. J Trauma. 2008;65(5):986-93.

39. Gunter Jr OL, Au BK, Isbell JM, Mowery NT, Young PP, Cotton BA. Optimizing outcomes in damage control resuscitation: identifying blood product ratios associated with improved survival. J Trauma. 2008;65(3):527-34.

40. Duchesne JC, Islam TM, Stuke L, Timmer JR, Barbeau JM, Marr AB, et al. Hemostatic resuscitation during surgery improves survival in patients with traumatic-induced coagulopathy. J Trauma. 2009;67(1):33-7. discussion 37-9.

41. Snyder CW, Weinberg JA, McGwin Jr G, Melton SM, George RL, Reiff DA, et al. The relationship of blood product ratio to mortality: survival benefit or survival bias? J Trauma. 2009;66(2):358-62. discussion 362-4.

42. Holcomb JB, del Junco DJ, Fox EE, Wade CE, Cohen MJ, Schreiber MA, et al. The prospective, observational, multicenter, major trauma transfusion (PROMMTT) study: comparative effectiveness of a time-varying treatment with competing risks. JAMA Surg. 2013;148(2):127-36.

43. Hagiwara A, Kushimoto S, Kato H, Sasaki J, Ogura H, Matsuoka T, et al. Can early aggressive administration of fresh frozen plasma improve outcomes in patients with severe blunt trauma? - a report by the Japanese Association for the Surgery of Trauma. Shock. 2016;45(5):495-501.

44. Holcomb JB, Tilley BC, Baraniuk S, Fox EE, Wade CE, Podbielski JM, et al. Transfusion of plasma, platelets, and red blood cells in a 1:1:1 vs a 1:1:2 ratio and mortality in patients with severe trauma: the PROPPR randomized clinical trial. JAMA. 2015;313(5):471-82.

45. Tieu BH, Holcomb JB, Schreiber MA. Coagulopathy: its pathophysiology and treatment in the injured patient. World J Surg. 2007;31(5):1055-64.

46. Rossaint R, Bouillon B, Cerny V, Coats TJ, Duranteau J, Fernandez-Mondejar E, et al. Management of bleeding following major trauma: an updated European guideline. Crit Care. 2010;14(2):R52.

47. Brohi K, Cohen MJ, Davenport RA. Acute coagulopathy of trauma: mechanism, identification and effect. Curr Opin Crit Care. 2007;13(6):680-5.

48. Kaafarani HM, Velmahos GC. Damage control resuscitation in trauma. Scand J Surg. 2014;103(2):81-8.

49. Husain FA, Martin MJ, Mullenix PS, Steele SR, Elliott DC. Serum lactate and base deficit as predictors of mortality and morbidity. Am J Surg. 2003;185(5):485-91.

50. Vandromme MJ, Griffin RL, Weinberg JA, Rue 3rd LW, Kerby JD. Lactate is a better predictor than systolic blood pressure for determining blood requirement and mortality: could prehospital measures improve trauma triage? J Am Coll Surg. 2010;210(5):861-7.
51. Shakur H, Roberts I, Bautista R, Caballero J, Coats T, Dewan Y, et al. Effects of tranexamic acid on death, vascular occlusive events, and blood transfusion in trauma patients with significant haemorrhage (CRASH-2): a randomised, placebo-controlled trial. Lancet. 2010;376(9734):23-32.

52. Moore HB, Moore EE, Liras IN, Gonzalez E, Harvin JA, Holcomb JB, et al. Acute fibrinolysis shutdown after injury occurs frequently and increases mortality: a multicenter evaluation of 2,540 severely injured patients. J Am Coll Surg. 2016;222(4):347-55.

53. Moore HB, Moore EE, Gonzalez E, Chapman MP, Chin TL, Silliman CC, et al. Hyperfibrinolysis, physiologic fibrinolysis, and fibrinolysis shutdown: the spectrum of postinjury fibrinolysis and relevance to antifibrinolytic therapy. J Trauma Acute Care Surg. 2016;77(6):811-7.

54. Hiippala ST, Myllyla GJ, Vahtera EM. Hemostatic factors and replacement of major blood loss with plasma-poor red cell concentrates. Anesth Analg. 1995;81(2):360-5.

55. Wafaisade A, Lefering R, Maegele M, Brockamp T, Mutschler M, Lendemans $S$, et al. Administration of fibrinogen concentrate in exsanguinating trauma patients is associated with improved survival at 6 hours but not at discharge. J Trauma Acute Care Surg. 2013;74(2):387-3. discussion 393-5.

56. Ponschab M, Voelckel W, Pavelka M, Schlimp CJ, Schochl H. Effect of coagulation factor concentrate administration on ROTEM(R) parameters in major trauma. Scand J Trauma Resus Emerg Med. 2015;23:84.

57. Schochl H, Nienaber U, Hofer G, Voelckel W, Jambor C, Scharbert G, et al. Goal-directed coagulation management of major trauma patients using thromboelastometry (ROTEM)-guided administration of fibrinogen concentrate and prothrombin complex concentrate. Crit Care. 2010;14(2):R55.

58. Curry N, Rourke C, Davenport R, Beer S, Pankhurst L, Deary A, et al. Early cryoprecipitate for major haemorrhage in trauma: a randomised controlled feasibility trial. Br J Anaesth. 2015;115(1):76-83.

59. Holcomb JB, Fox EE, Zhang X, White N, Wade CE, Cotton BA, et al. Cryoprecipitate use in the Prospective Observational Multicenter Major Trauma Transfusion study (PROMMTT). J Trauma Acute Care Surg. 2013; 75(1 Suppl 1):S31-9.

60. Olaussen A, Fitzgerald MC, Tan GA, Mitra B. Cryoprecipitate administration after trauma. Eur J Emerg Med. 2016;23(4):269-73.

61. Ho KM, Leonard AD. Concentration-dependent effect of hypocalcaemia on mortality of patients with critical bleeding requiring massive transfusion: a cohort study. Anaesth Intensive Care. 2011;39(1):46-54.

62. Magnotti LJ, Bradburn EH, Webb DL, Berry SD, Fischer PE, Zarzaur BL, et al. Admission ionized calcium levels predict the need for multiple transfusions: a prospective study of 591 critically ill trauma patients. J Trauma. 2011;70(2): 391-5. discussion 395-7.

63. Lier H, Bottiger BW, Hinkelbein J, Krep H, Bernhard M. Coagulation management in multiple trauma: a systematic review. Intensive Care Med. 2011;37(4):572-82.

64. Jansen JO, Thomas R, Loudon MA, Brooks A. Damage control resuscitation for patients with major trauma. BMJ. 2009;338:b1778.

65. Perkins JG, Cap AP, Weiss BM, Reid TJ, Bolan CD. Massive transfusion and nonsurgical hemostatic agents. Crit Care Med. 2008;36(7 Suppl):S325-39.

66. Bawazeer M, Ahmed N, Izadi H, McFarlan A, Nathens A, Pavenski K. Compliance with a massive transfusion protocol (MTP) impacts patient outcome. Injury. 2015;46(1):21-8.

67. Riskin DJ, Tsai TC, Riskin L, Hernandez-Boussard T, Purtill M, Maggio PM, et al. Massive transfusion protocols: the role of aggressive resuscitation versus product ratio in mortality reduction. J Am Coll Surg. 2009; 209(2):198-205.

68. Duchesne JC, Kimonis K, Marr AB, Rennie KV, Wahl G, Wells JE, et al. Damage control resuscitation in combination with damage control laparotomy: a survival advantage. J Trauma. 2010;69(1):46-52.

69. Schuster KM, Davis KA, Lui FY, Maerz LL, Kaplan L. The status of massive transfusion protocols in United States trauma centers: massive transfusion or massive confusion? Transfusion. 2010;50(7):1545-51.

70. Cotton BA, Gunter OL, Isbell J, Au BK, Robertson AM, Morris Jr JA, et al. Damage control hematology: the impact of a trauma exsanguination protocol on survival and blood product utilization. J Trauma. 2008;64(5): 1177-82. discussion 1182-3.

71. Dente CJ, Shaz BH, Nicholas JM, Harris RS, Wyrzykowski AD, Patel S, et al. Improvements in early mortality and coagulopathy are sustained better in patients with blunt trauma after institution of a massive transfusion protocol in a civilian level I trauma center. J Trauma. 2009;66(6):1616-24. 
72. Cinat ME, Wallace WC, Nastanski F, West J, Sloan S, Ocariz J, et al. Improved survival following massive transfusion in patients who have undergone trauma. Arch Surg. 1999;134(9):964-8. discussion 968-70.

73. Inaba K, Branco BC, Rhee P, Blackbourne LH, Holcomb JB, Teixeira PG, et al. Impact of plasma transfusion in trauma patients who do not require massive transfusion. J Am Coll Surg. 2010;210(6):957-65.

74. Yucel N, Lefering R, Maegele M, Vorweg M, Tjardes T, Ruchholtz S, et al. Trauma Associated Severe Hemorrhage (TASH)-Score: probability of mass transfusion as surrogate for life threatening hemorrhage after multiple trauma. J Trauma. 2006;60(6):1228-36. discussion 1236-7.

75. McLaughlin DF, Niles SE, Salinas J, Perkins JG, Cox ED, Wade CE, et al. A predictive model for massive transfusion in combat casualty patients. J Trauma. 2008;64(2 Suppl):S57-63. discussion S63.

76. Nunez TC, Voskresensky IV, Dossett LA, Shinall R, Dutton WD, Cotton BA. Early prediction of massive transfusion in trauma: simple as $A B C$ (assessment of blood consumption)? J Trauma. 2009;66(2):346-52.

77. Ogura T, Nakamura Y, Nakano M, Izawa Y, Nakamura M, Fujizuka K, et al. Predicting the need for massive transfusion in trauma patients: the Traumatic Bleeding Severity Score. J Trauma Acute Care Surg. 2014;76(5):1243-50.

78. Ogura T, Lefor AK, Masuda M, Kushimoto S. Modified traumatic bleeding severity score: early determination of the need for massive transfusion. Am J Emerg Med. 2016;34(6):1097-101.

79. Gerhardt RT, Strandenes G, Cap AP, Rentas FJ, Glassberg E, Mott J, et al. Remote damage control resuscitation and the Solstrand Conference: defining the need, the language, and a way forward. Transfusion. 2013; 53 Suppl 1:9S-16S.

80. Ausset S, Glassberg E, Nadler R, Sunde G, Cap AP, Hoffmann C, et al. Tranexamic acid as part of remote damage-control resuscitation in the prehospital setting: a critical appraisal of the medical literature and available alternatives. J Trauma Acute Care Surg. 2015;78(6 Suppl 1):S70-5.

81. Wafaisade A, Lefering R, Bouillon B, Bohmer AB, Gassler M, Ruppert M. Prehospital administration of tranexamic acid in trauma patients. Crit Care. 2016;20(1):143

82. Spahn DR, Bouillon B, Cerny V, Coats TJ, Duranteau J, Fernandez-Mondejar E, et al. Management of bleeding and coagulopathy following major trauma: an updated European guideline. Crit Care. 2013;17(2):R76.

83. Stone HH, Strom PR, Mullins RJ. Management of the major coagulopathy with onset during laparotomy. Ann Surg. 1983;197(5):532-5.

84. Vargo DJ, Battistella FD. Abbreviated thoracotomy and temporary chest closure: an application of damage control after thoracic trauma. Arch Surg. 2001;136(1):21-4

85. Rasmussen TE, Clouse WD, Jenkins DH, Peck MA, Eliason JL, Smith DL. The use of temporary vascular shunts as a damage control adjunct in the management of wartime vascular injury. J Trauma. 2006;61(1):8-12.

86. Henry SM, Tornetta 3rd P, Scalea TM. Damage control for devastating pelvic and extremity injuries. Surg Clin North Am. 1997;77(4):879-95.

87. Scalea TM, Boswell SA, Scott JD, Mitchell KA, Kramer ME, Pollak AN. External fixation as a bridge to intramedullary nailing for patients with multiple injuries and with femur fractures: damage control orthopedics. J Trauma. 2000;48(4):613-21. discussion 621-3.

88. Pape HC, Hildebrand F, Pertschy S, Zelle B, Garapati R, Grimme K, et al. Changes in the management of femoral shaft fractures in polytrauma patients: from early total care to damage control orthopedic surgery. J Trauma. 2002;53(3):452-61. discussion 461-2.

89. Sutton E, Bochicchio GV, Bochicchio K, Rodriguez ED, Henry S, Joshi M, et al. Long term impact of damage control surgery: a preliminary prospective study. J Trauma. 2006;61(4):831-4. discussion 835-6.

90. Johnson JW, Gracias VH, Schwab CW, Reilly PM, Kauder DR, Shapiro MB, et al. Evolution in damage control for exsanguinating penetrating abdominal injury. J Trauma. 2001;51(2):261-9. discussion 269-71.

91. Smith BP, Adams RC, Doraiswamy VA, Nagaraja V, Seamon MJ, Wisler J, et al. Review of abdominal damage control and open abdomens: focus on gastrointestinal complications. J Gastrointestin Liver Dis. 2010;19(4):425-35

92. Diaz Jr JJ, Dutton WD, Ott MM, Cullinane DC, Alouidor R, Armen SB, et al. Eastern Association for the Surgery of Trauma: a review of the management of the open abdomen-part 2 "Management of the open abdomen". J Trauma. 2011;71(2):502-12.

93. Dubose JJ, Lundy JB. Enterocutaneous fistulas in the setting of trauma and critical illness. Clin Colon Rectal Surg. 2010;23(3):182-9.

94. Cotton BA, Reddy N, Hatch QM, LeFebvre E, Wade CE, Kozar RA, et al. Damage control resuscitation is associated with a reduction in resuscitation volumes and improvement in survival in 390 damage control laparotomy patients. Ann Surg. 2011;254(4):598-605.

95. Roberts DJ, Bobrovitz N, Zygun DA, Ball CG, Kirkpatrick AW, Faris PD, et al. Indications for use of damage control surgery in civilian trauma patients: a content analysis and expert appropriateness rating study. Ann Surg. 2016;263(5):1018-27.

96. Higa G, Friese R, O'Keeffe T, Wynne J, Bowlby P, Ziemba M, et al. Damage control laparotomy: a vital tool once overused. J Trauma. 2010;69(1):53-9.

97. Holcomb JB, Jenkins D, Rhee P, Johannigman J, Mahoney P, Mehta S, et al. Damage control resuscitation: directly addressing the early coagulopathy of trauma. J Trauma. 2007:62(2):307-10.

98. Schreiber MA. The beginning of the end for damage control surgery. Br J Surg. 2012;99 Suppl 1:10-1.

99. Bradley M, Galvagno S, Dhanda A, Rodriguez C, Lauerman M, DuBose J, et al. Damage control resuscitation protocol and the management of open abdomens in trauma patients. Am Surg. 2014;80(8):768-75.

100. Shrestha B, Holcomb JB, Camp EA, Del Junco DJ, Cotton BA, Albarado R, et al. Damage-control resuscitation increases successful nonoperative management rates and survival after severe blunt liver injury. J Trauma Acute Care Surg. 2015;78(2):336-41.

\section{Submit your next manuscript to BioMed Central and we will help you at every step:}

- We accept pre-submission inquiries

- Our selector tool helps you to find the most relevant journal

- We provide round the clock customer support

- Convenient online submission

- Thorough peer review

- Inclusion in PubMed and all major indexing services

- Maximum visibility for your research

Submit your manuscript at www.biomedcentral.com/submit
Biomed Central 